\title{
Country of Manufacture
}

National Cancer Institute

\section{Source}

National Cancer Institute. Country of Manufacture. NCI Thesaurus. Code C124455.

The name of the country within which the product under study is made. 